\title{
Effect of radiation on convective flow in a tilted solar collector filled with water-alumina nanofluid
}

\author{
Rehena Nasrin* and M. A. Alim \\ Department of Mathematics, Bangladesh University of Engineering and Technology, Dhaka - 1000, BANGLADESH \\ "Corresponding author: E-mail: rehena@math.buet.ac.bd
}

\begin{abstract}
The effect of radiation on natural convective flow inside a solar collector having a flat-plate cover and a sine-wave absorber is analyzed numerically. The solar collector is filled with water- $\mathrm{Al}_{2} \mathrm{O}_{3}$ nanofluid. The governing differential equations with boundary conditions are solved by the Penalty Finite Element Method using Galerkin's weighted residual scheme. The effects of radiation $(\varepsilon)$ and tilted angle $(\psi)$ on the flow and heat transfer characteristics are simulated. In addition average Nusselt number, average temperature and mean velocity field for nanofluid within the collector are presented graphically for the governing parameters mentioned above. The highest heat transfer rate is observed for the largest $\varepsilon$ and absence of $\psi$. The $\mathrm{Al}_{2} \mathrm{O}_{3}$ nanoparticles with the highest $\varepsilon$ and in absence of $\psi$ are established to be most effective in enhancing performance of heat transfer rate. Moreover, increasing tilted angle $\psi$ and lessening emissivity $\varepsilon$ cause decrease of average fluid temperature. For growing both parameters mean velocity field increases.
\end{abstract}

Keywords: Radiation, tilted solar collector, finite element method, water- alumina nanofluid.

DOI: http://dx.doi.org/10.4314/ijest.v4i4.1

\section{Introduction}

Solar collectors are key elements in many applications, such as building heating systems, solar drying devices, etc. Solar energy has the greatest potential of all the sources of renewable energy especially when other sources in the country have depleted. Because of the desirable environmental and safety aspects it is widely believed that solar energy should be utilized instead of other alternative energy forms, even when the costs involved are slightly higher. The flat-plate solar collector is commonly used today for the collection of low temperature solar thermal energy. The fluids with solid-sized nanoparticles suspended in them are called "nanofluids". The natural convection in enclosures continues to be a very active area of research during the past few decades. Applications of nanoparticles in thermal field are to enhance heat transfer from solar collectors to storage tanks, to improve efficiency of coolants in transformers etc. Performance of solar collector is to transfer solar energy into thermal energy.

Rao (1977) proposed a two-dimensional model for the absorber plate conduction to compute the fluid temperature rise. Kreith (1978) stated that the sun is a sphere of intensely hot gaseous matter with a diameter of $1.39 \times 10^{9} \mathrm{~m}$. The solar energy strikes our planet a mere $8 \mathrm{~min}$ and $20 \mathrm{~s}$ after leaving the giant furnace. The sun has an effective blackbody temperature of $5762 \mathrm{~K}$. Various investigators have used two dimensional conduction equations in their analysis with different boundary conditions. A twodimensional model for the transfer of heat in flat plate solar collector absorbers with adiabatic boundary conditions at the upper and lower edges of the collector is proposed by Lund (1986). He solved approximately the governing partial differential equations analytically in terms of perturbation series. The one-dimensional analysis offers a desired accuracy required in a routine analysis even though a two-dimensional temperature distribution exists over the absorber plate of the collector. Therefore, for more accurate analysis at low mass flow rates, a two-dimensional temperature distribution must be considered.

Nag et al. (1989) used the two-dimensional model proposed by Lund, but with convection boundary condition at the upper and lower edge of the absorber plate. They solved the governing equations using finite element method. They concluded that the 
isotherms deviated from a one-dimensional pattern for a high flow rate to a predominantly two-dimensional distribution for a low mass flow rate. Conventional analysis and design of solar collector is based on a one-dimensional conduction equation formulation of Sukhatme (1991). The analysis has been substantially assisted by the derivation of plate-fin efficiency factors. The factors relate the design and operating conditions of the collector in a systematic manner that facilitates prediction of heat collection rates at the design stage. Piao et al. $(1992,1994)$ investigated experimentally natural, forced and mixed convective heat transfer in a crosscorrugated channel solar air heater. Detailed experimental and numerical studies on the performance of the solar air heater were made by Gao (1996). Noorshahi et al. (1996) studied numerically on the natural convection in a corrugated enclosure with mixed boundary conditions. Stasiek (1998) made experimental studies of heat transfer and fluid flow across corrugated and undulated heat exchanger surfaces.

There are so many methods introduced to increase the efficiency of the solar water heater Xuesheng et al. (2005), Xiaowu (2005), Hussain (2006) and Ho and Chen (2006). But the novel approach is to introduce the nanofluids in solar water heater instead of conventional heat transfer fluids (like water). The poor heat transfer properties of these conventional fluids compared to most solids are the primary obstacle to the high compactness and effectiveness of the system. The essential initiative is to seek the solid particles having thermal conductivity of several hundred times higher than those of conventional fluids. An innovative idea is to suspend ultra fine solid particles in the fluid for improving the thermal conductivity of the fluid Hetsroni and Rozenblit (1994). These early studies, however, used suspensions of millimeter- or micrometer-sized particles, which, although showed some enhancement, experienced problems such as poor suspension stability and hence channel clogging, which are particularly serious for systems using mini sized and micro sized particles. The suspended metallic or nonmetallic nanoparticles change the transport properties and heat transfer characteristics of the base fluid. Stability and thermal conductivity characteristics of nanofluids was performed by Hwang et al. (2007). In this study, they concluded that the thermal conductivity of ethylene glycol was increased by $30 \%$.

The absorptance of the collector surface for shortwave solar radiation depends on the nature and colour of the coating and on the incident angle. Usually black colour is used. Various colour coatings had been proposed in Tripanagnostopoulos et al. (2000), Orel et al. (2002) and Wazwaz et al. (2002) mainly for aesthetic reasons. The principal requirement of the solar collector is a large contact area between the absorbing surface and the air. Various applications of solar air collectors are reported by Kolb et al. (1999). Role of nanofluids in solar water heater was studied by Natarajan \& Sathish (2009). They concluded that the suspended metallic or nonmetallic nanoparticles change the transport properties and heat transfer characteristics of the base fluid. Nanofluids are expected to exhibit superior heat transfer properties compared with conventional heat transfer fluids. The aim of this paper is to analyze and compare the heat transfer properties of the nanofluids with the conventional fluids. A low-cost mechanically manufactured selective solar absorber surface method had been proposed by Konttinen et al. (2003). Another category of collectors is the uncovered or unglazed solar collector Soltau (1992). These are usually low-cost units which can offer cost effective solar thermal energy in applications such as water preheating for domestic or industrial use, heating of swimming pools Molineaux et al. (1994), space heating and air heating for industrial or agricultural applications.

In this paper, the influences of radiation and tilted angle on natural convection flow inside the solar collector having the flatplate cover and wavelike absorber are numerically investigated.

\section{Physical Configuration}

Fig. 1 shows a schematic diagram of a tilted solar collector. The fluid in the collector is water-based nanofluid containing $\mathrm{Al}_{2} \mathrm{O}_{3}$ nanoparticles. The nanofluid is assumed incompressible and the flow is considered to be laminar. It is taken that the water and nanoparticles are in thermal equilibrium and no slip occurs between them. The solar collector is a metal box with a cover plate on top and a dark colored wavelike absorber plate on the bottom. The top horizontal wall initially has constant temperature $T_{h}$, while the bottom sinusoidal wall is at temperature $T_{c}$, with $T_{h}>T_{c}$. The two vertical walls are considered adiabatic. The top wall takes as transparent glass cover plate to collect enough solar heat directly. That's why bottom absorber is taken as cool. As a result the solar energy is transferred into thermal energy by this model. The density of the nanofluid is approximated by the Boussinesq model. Only the steady state case is considered. In addition, if we input the cold water through the entrance of the passage (below the absorber and above the insulation), then the cold water becomes hot in contact with the absorber and we get the hot water from the exit of this passage. This hot water can be used in various purposes.

The thermophysical properties of the nanofluid are taken from Lin and Violi (2010) and given in Table 1.

Table 1: Thermo physical properties of fluid and nanoparticles

\begin{tabular}{ccc}
\hline Physical Properties & Fluid phase (Water) & $\mathrm{Al}_{2} \mathrm{O}_{3}$ \\
\hline$C_{p}(\mathrm{~J} / \mathrm{kgK})$ & 4179 & 850 \\
$\rho\left(\mathrm{kg} / \mathrm{m}^{3}\right)$ & 997.1 & 3900 \\
$k(\mathrm{~W} / \mathrm{mK})$ & 0.613 & 46 \\
$\beta(1 / \mathrm{K})$ & $21 \times 10^{-5}$ & $1.67 \times 10^{-5}$ \\
\hline
\end{tabular}




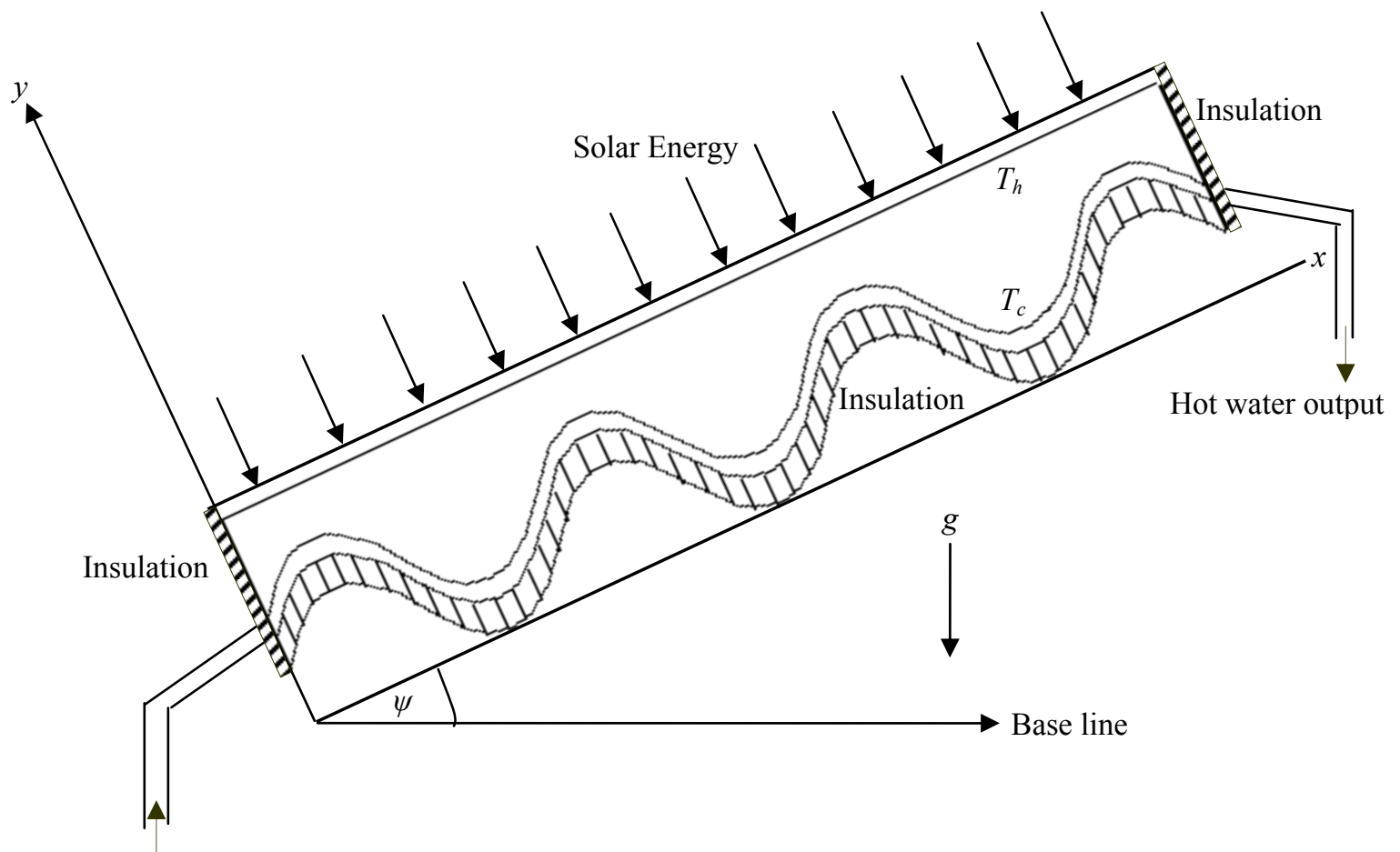

Cold water input

Fig.1: Schematic diagram of the Solar Collector

\section{Mathematical Formulation}

The governing equations for laminar, steady-state natural convection in an annulus filled with water-alumina nanofluid in terms of the Navier-Stokes and energy equation are given as:

Continuity equation:

$\frac{\partial u}{\partial x}+\frac{\partial v}{\partial y}=0$

$x$-momentum equation:

$\rho_{n f}\left(u \frac{\partial u}{\partial x}+v \frac{\partial u}{\partial y}\right)=-\frac{\partial p}{\partial x}+\mu_{n f}\left(\frac{\partial^{2} u}{\partial x^{2}}+\frac{\partial^{2} u}{\partial y^{2}}\right)+g \rho_{n f} \beta_{n f}\left(T-T_{c}\right) \sin \psi$

$y$-momentum equation:

$\rho_{n f}\left(u \frac{\partial v}{\partial x}+v \frac{\partial v}{\partial y}\right)=-\frac{\partial p}{\partial y}+\mu_{n f}\left(\frac{\partial^{2} v}{\partial x^{2}}+\frac{\partial^{2} v}{\partial y^{2}}\right)+g \rho_{n f} \beta_{n f}\left(T-T_{c}\right) \cos \psi$

Energy equation:

$u \frac{\partial T}{\partial x}+v \frac{\partial T}{\partial y}=\alpha_{n f}\left(\frac{\partial^{2} T}{\partial x^{2}}+\frac{\partial^{2} T}{\partial y^{2}}\right)$

where, $\rho_{n f}=(1-\phi) \rho_{f}+\phi \rho_{s}$ is the density,

$\left(\rho C_{p}\right)_{n f}=(1-\phi)\left(\rho C_{p}\right)_{f}+\phi\left(\rho C_{p}\right)_{s}$ is the heat capacitance,

$\beta_{n f}=(1-\phi) \beta_{f}+\phi \beta_{s}$ is the thermal expansion coefficient, 
$\alpha_{n f}=k_{n f} /\left(\rho C_{p}\right)_{n f}$ is the thermal diffusivity,

the dynamic viscosity of the Brinkman model (1952) is $\mu_{n f}=\mu_{f}(1-\phi)^{-2.5}$

and the thermal conductivity of the Maxwell Garnett (MG) model (1904) is $k_{n f}=k_{f} \frac{k_{s}+2 k_{f}-2 \phi\left(k_{f}-k_{s}\right)}{k_{s}+2 k_{f}+\phi\left(k_{f}-k_{s}\right)}$.

Radiation heat transfer by the top glass cover surface must account for the thermal radiation which can be absorbed, reflected, or transmitted. This decomposition can be expressed by,

$q_{\text {net }}=q_{\text {absorbed }}+q_{\text {transmitted }}+q_{\text {reflected }}$

Outside the boundary layer, the amount of energy $q_{\text {reflected }}$ is neglected.

Thus total energy of the glass cover plate becomes $q_{\text {net }}=q_{\text {absorbed }}+q_{\text {transmitted }}$

Now the amount of transmitted energy is radiated from the cover plate to the bottom wavy absorber without any medium as:

$q_{\text {transmitted }}=q_{r}=\varepsilon \sigma A\left(T_{w}^{4}-T_{c}^{4}\right)$

Here $\varepsilon$ is emissivity (radiation parameter) of the glass cover plate, $\sigma$ is the Stefan Boltzmann constant $5.670400 \times 10^{-8} \mathrm{Js}^{-1} \mathrm{~m}^{-2} \mathrm{~K}^{-4}$ and $T_{w}$ is the variable temperature of the top wall. Again, the amount of absorbed energy is transferred from cover plate to bottom absorber by natural convection where medium is nanofluid as:

$q_{\text {absorbed }}=q_{c}=h A\left(T_{w}-T_{i}\right)$

So total energy gained or lost by the cover plate is $q_{n e t}=h A\left(T_{w}-T_{i}\right)+\varepsilon \sigma A\left(T_{w}{ }^{4}-T_{c}^{4}\right)$

The boundary conditions are:

at all solid boundaries $u=v=0$

at the vertical walls $\frac{\partial T}{\partial x}=0$

at the top cover plate $q=h A\left(T_{w}-T_{i}\right)+\varepsilon \sigma A\left(T_{w}{ }^{4}-T_{c}^{4}\right)$

at the bottom wavy absorber $T=T_{c}$

The above equations are non-dimensionalized by using the following dimensionless dependent and independent variables:

$X=\frac{x}{L}, \quad Y=\frac{y}{L}, \quad U=\frac{u L}{v_{f}}, \quad V=\frac{v L}{v_{f}}, \quad P=\frac{p L^{2}}{\rho_{f} v_{f}^{2}}, \theta=\frac{T-T_{c}}{T_{h}-T_{c}}$

Then the non-dimensional governing equations are

$\frac{\partial U}{\partial X}+\frac{\partial V}{\partial Y}=0$

$U \frac{\partial U}{\partial X}+V \frac{\partial U}{\partial Y}=-\frac{\rho_{f}}{\rho_{n f}} \frac{\partial P}{\partial X}+\frac{v_{n f}}{v_{f}}\left(\frac{\partial^{2} U}{\partial X^{2}}+\frac{\partial^{2} U}{\partial Y^{2}}\right)+\frac{R a}{P r} \frac{(1-\phi) \rho_{f} \beta_{f}+\phi \rho_{s} \beta_{s}}{\rho_{n f} \beta_{f}} \theta \sin \psi$

$U \frac{\partial V}{\partial X}+V \frac{\partial V}{\partial Y}=-\frac{\rho_{f}}{\rho_{n f}} \frac{\partial P}{\partial Y}+\frac{v_{n f}}{v_{f}}\left(\frac{\partial^{2} V}{\partial X^{2}}+\frac{\partial^{2} V}{\partial Y^{2}}\right)+\frac{R a}{P r} \frac{(1-\phi) \rho_{f} \beta_{f}+\phi \rho_{s} \beta_{s}}{\rho_{n f} \beta_{f}} \theta \cos \psi$ 
$U \frac{\partial \theta}{\partial X}+V \frac{\partial \theta}{\partial Y}=\frac{1}{\operatorname{Pr}}\left(\frac{\partial^{2} \theta}{\partial X^{2}}+\frac{\partial^{2} \theta}{\partial Y^{2}}\right)$

where $\operatorname{Pr}=\frac{v_{f}}{\alpha_{f}}$ is the Prandtl number, $R a=\frac{g \beta_{f} L^{3}\left(T_{h}-T_{c}\right)}{v_{f} \alpha_{f}}$ is the Rayleigh number.

The corresponding boundary conditions take the following form:

at all solid boundaries $U=V=0$

at the vertical walls $\frac{\partial \theta}{\partial X}=0$

at the bottom wavy absorber $\theta=0$

The shape of the bottom wavy absorber profile is assumed to mimic the following pattern $Y=A_{m}[1-\cos (2 \lambda \pi X)]$ where $A_{m}$ is the dimensionless amplitude of the wavy surface and $\lambda$ is the number of undulations.

The average Nusselt number $(\mathrm{Nu})$ is expected to depend on a number of factors such as thermal conductivity, heat capacitance, viscosity, flow structure of nanofluids, volume fraction, dimensions and fractal distributions of nanoparticles. The local variation of the convective Nusselt number of the fluid at the top cover plate is $N u_{c l}=-\frac{k_{n f}}{k_{f}} \frac{\partial T}{\partial y}$.

The non-dimensional form of local convective heat transfer is $N u_{c l}=-\frac{k_{n f}}{k_{f}} \frac{\partial \theta}{\partial Y}$.

By integrating the local Nusselt number over the top heated surface, the average convective heat transfer along the cover plate of the collector is used by Saleh et al. (2011) as $N u_{c}=\int_{0}^{1} N u_{c l} d X$.

The radiative heat transfer rate is expressed as $\quad N u_{r}=\int_{0}^{1} q_{r} d X$.

The average Nusselt number is $N u=N u_{c}+N u_{r}$

The mean bulk temperature and average velocity field of the nanofluid inside the tilted collector may be written as $\theta_{a v}=\int \theta d \bar{V} / \bar{V}$ and $\omega_{a v}=\int \omega d \bar{V} / \bar{V}$, where $\bar{V}$ is the volume of the collector.

\section{Numerical Computation}

The Galerkin finite element method from Taylor and Hood (1973) and Dechaumphai (1999) is used to solve the nondimensional governing equations along with boundary conditions for the considered problem. The equation of continuity has been used as a constraint due to mass conservation and this restriction may be used to find the pressure distribution. The penalty finite element method from Basak et al. (2009) is used to solve the Eqs. (6) - (8), where the pressure $P$ is eliminated by a penalty constraint $\xi$, and the incompressibility criteria given by equation (8) which can be expressed as

$$
P=-\xi\left(\frac{\partial U}{\partial X}+\frac{\partial V}{\partial Y}\right)
$$

The continuity equation is automatically fulfilled for large values of $\xi$. Then the velocity components $(U, V)$, and temperature $(\theta)$ are expanded using a basis set $\{\Phi\}_{k=1}^{N}$ as $U \approx \sum_{k=1}^{N} U_{k} \Phi_{k}(X, Y), \quad V \approx \sum_{k=1}^{N} V_{k} \Phi_{k}(X, Y)$ and $\quad \theta \approx \sum_{k=1}^{N} \theta_{k} \Phi_{k}(X, Y)$

The Galerkin finite element technique yields the subsequent nonlinear residual equations for the Eqs. (6), (7) and (8) respectively at nodes of the internal domain $\Omega$ : 


$$
\begin{aligned}
R_{i}^{(1)}= & \sum_{k=1}^{N} U_{k} \int_{\Omega}\left[\left(\sum_{k=1}^{N} U_{k} \Phi_{k}\right) \frac{\partial \Phi_{k}}{\partial X}+\left(\sum_{k=1}^{N} V_{k} \Phi_{k}\right) \frac{\partial \Phi_{k}}{\partial Y}\right] \Phi_{i} d X d Y-\xi \frac{\rho_{f}}{\rho_{n f}}\left[\sum_{k=1}^{N} U_{k} \int_{\Omega} \frac{\partial \Phi_{i}}{\partial X} \frac{\partial \Phi_{k}}{\partial X} d X d Y+\sum_{k=1}^{N} V_{k} \int_{\Omega} \frac{\partial \Phi_{i}}{\partial Y} \frac{\partial \Phi_{k}}{\partial Y} d X d Y\right] \\
& -\frac{v_{n f}}{v_{f}} \sum_{k=1}^{N} U_{k} \int_{\Omega}\left[\frac{\partial \Phi_{i}}{\partial X} \frac{\partial \Phi_{k}}{\partial X}+\frac{\partial \Phi_{i}}{\partial Y} \frac{\partial \Phi_{k}}{\partial Y}\right] d X d Y-\frac{R a}{P r} \sin \psi \frac{(1-\phi) \rho_{f} \beta_{f}+\phi \rho_{s} \beta_{s}}{\rho_{n f} \beta_{f}} \int_{\Omega}\left(\sum_{k=1}^{N} \theta_{k} \Phi_{k}\right) \Phi_{i} d X d Y \\
R_{i}^{(2)}= & \sum_{k=1}^{N} V_{k} \int_{\Omega}\left[\left(\sum_{k=1}^{N} U_{k} \Phi_{k}\right) \frac{\partial \Phi_{k}}{\partial X}+\left(\sum_{k=1}^{N} V_{k} \Phi_{k}\right) \frac{\partial \Phi_{k}}{\partial Y}\right] \Phi_{i} d X d Y-\xi \frac{\rho_{f}}{\rho_{n f}}\left[\sum_{k=1}^{N} U_{k} \int_{\Omega} \frac{\partial \Phi_{i}}{\partial X} \frac{\partial \Phi_{k}}{\partial X} d X d Y+\sum_{k=1}^{N} V_{k} \int_{\Omega} \frac{\partial \Phi_{i}}{\partial Y} \frac{\partial \Phi_{k}}{\partial Y} d X d Y\right] \\
& -\frac{v_{n f}}{v_{f}} \sum_{k=1}^{N} V_{k} \int_{\Omega}\left[\frac{\partial \Phi_{i}}{\partial X} \frac{\partial \Phi_{k}}{\partial X}+\frac{\partial \Phi_{i}}{\partial Y} \frac{\partial \Phi_{k}}{\partial Y}\right] d X d Y-\frac{R a}{P r} \cos \psi \frac{(1-\phi) \rho_{f} \beta_{f}+\phi \rho_{s} \beta_{s}}{\rho_{n f} \beta_{f}} \int_{\Omega}\left(\sum_{k=1}^{N} \theta_{k} \Phi_{k}\right) \Phi_{i} d X d Y \\
R_{i}^{(3)}= & \sum_{k=1}^{N} \theta_{k}\left[\left(\sum_{\Omega}^{N}\left[U_{k=1} \Phi_{k}\right) \frac{\partial \Phi_{k}}{\partial X}+\left(\sum_{k=1}^{N} V_{k} \Phi_{k}\right) \frac{\partial \Phi_{k}}{\partial Y}\right] \Phi_{i} d X d Y-\frac{1}{P r} \sum_{k=1}^{N} \theta_{k} \int_{\Omega}\left[\frac{\partial \Phi_{i}}{\partial X} \frac{\partial \Phi_{k}}{\partial X}+\frac{\partial \Phi_{i}}{\partial Y} \frac{\partial \Phi_{k}}{\partial Y}\right] d X d Y\right.
\end{aligned}
$$

Three points Gaussian quadrature is used to evaluate the integrals in these equations. The non-linear residual equations (11), (12) and (13) are solved using the Newton-Raphson method to determine the coefficients of the expansions in Eq. (10). The convergence of solutions is assumed when the relative error for each variable between consecutive iterations is recorded below the convergence criterion $\varepsilon$ such that $\left|\Psi^{n+1}-\Psi^{n}\right| \leq 10^{-4}$, where $n$ is the number of iteration and $\Psi$ is a function of $U, V$ and $\theta$.

\subsection{Mesh Generation}

In the finite element method, the mesh generation is the technique to subdivide a domain into a set of sub-domains, called finite elements, control volume, etc. The discrete locations are defined by the numerical grid, at which the variables are to be calculated. It is basically a discrete representation of the geometric domain on which the problem is to be solved. The computational domains with irregular geometries by a collection of finite elements make the method a valuable practical tool for the solution of boundary value problems arising in various fields of engineering. Fig. 2 displays the finite element mesh of the present physical domain.

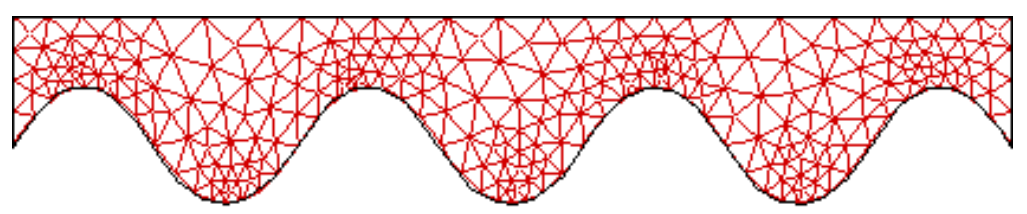

Fig. 2: Mesh generation of the fluid valve

\subsection{Grid Refinement Test}

An extensive mesh testing procedure is conducted to guarantee a grid-independent solution for $\psi=0^{0}, \varepsilon=0.1, \phi=5 \%, R a=$ $10^{4}$ and $\mathrm{Pr}=7$ in a solar collector. In the present work, we examine five different non-uniform grid systems with the following number of elements within the resolution field: 2969, 5130, 6916, 9057 and 11426. The numerical scheme is carried out for a highly precise key in the average convective and radiated Nusselt numbers namely $N u_{c}$ and $N u_{r}$ for the aforesaid elements to develop an understanding of the grid fineness as shown in Table 2 and Fig. 3. The scale of the average Nusselt number (convective and radiative) for 9057 elements shows a little difference with the results obtained for the other elements. Hence, considering the non-uniform grid system of 9057 elements is preferred for the computation. 
Table 2: Grid Sensitivity Check at $\varepsilon=0.1$ and $\psi=0^{0}$

\begin{tabular}{|c|c|c|c|c|c|}
\hline $\begin{array}{c}\text { Nodes } \\
(\text { elements })\end{array}$ & $\begin{array}{c}6224 \\
(2969)\end{array}$ & $\begin{array}{c}10982 \\
(5130)\end{array}$ & $\begin{array}{c}13538 \\
(6916)\end{array}$ & $\begin{array}{c}20295 \\
(9057)\end{array}$ & $\begin{array}{c}27524 \\
(11426)\end{array}$ \\
\hline$N u_{c}$ & 10.82945 & 12.48176 & 14.58701 & 15.875492 & 15.904362 \\
\hline$N u_{r}$ & 4.92945 & 5.68176 & 6.18701 & 7.00490 & 7.21746 \\
\hline Time (s) & 226.265 & 292.594 & 388.157 & 421.328 & 627.375 \\
\hline
\end{tabular}

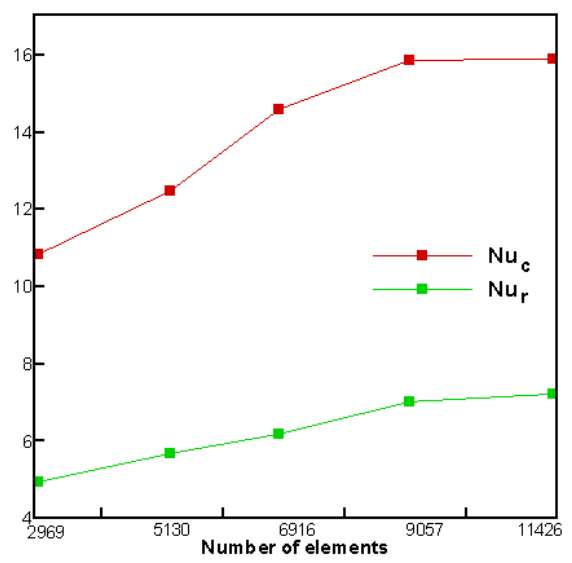

Fig. 3: Grid independency study for the geometry

\subsection{Code Validation}

The present numerical solution is validated by comparing the current code results for heat transfer - temperature difference profile at $\operatorname{Pr}=0.73, G r=10^{4}$ with the graphical representation of Gao et al. (2000) which was reported for heat transfer augmentation inside a channel between the flat-plate cover and the sine-wave absorber of a cross-corrugated solar air heater. Fig. 4 demonstrates the result of numerical simulations of the effect of $\Delta \mathrm{T}$ on the natural convection heat transfer coefficient $\mathrm{h}$. As shown in Fig. 4, $\Delta \mathrm{T}-\mathrm{h}$ profile of the numerical solutions (present code and Gao et al. (2000) are in good agreement.

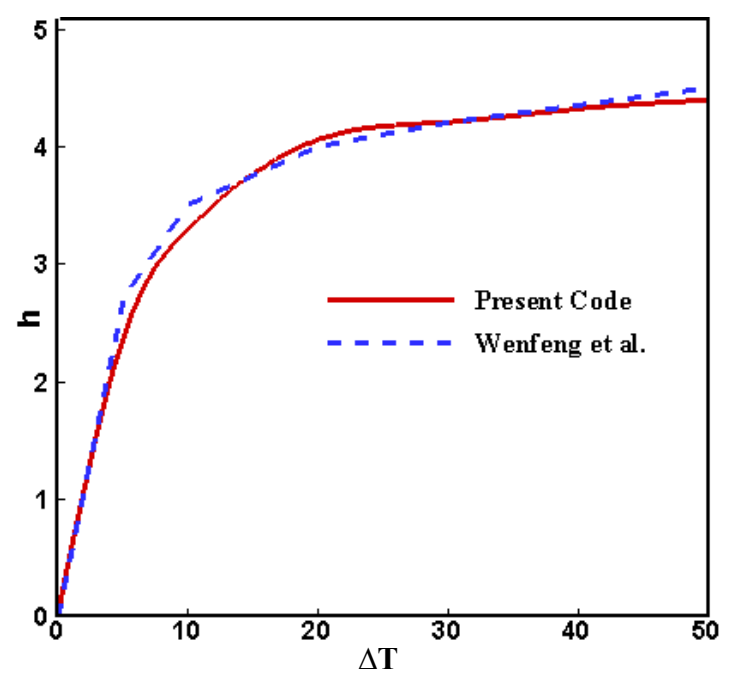

Fig. 4: Comparison between present code and Gao et al. (2000) at $\operatorname{Pr}=0.73$ and $R a=10^{4}$ 


\section{Results and Discussion}

In this section, numerical results of streamlines and isotherms for various values of emmisivity $(\varepsilon)$ and tilted angle $(\psi)$ with $\mathrm{Al}_{2} \mathrm{O}_{3}$ /water nanofluid in a solar collector are displayed. The considered values of $\varepsilon$ and $\psi$ are $\varepsilon=(0.1,0.4,0.7$ and 0.98$), \psi\left(=0^{0}\right.$, $30^{\circ}, 60^{\circ}$ and $80^{\circ}$ ) while the solid volume fraction $\phi=5 \%$, the wave amplitude of bottom surface $A_{m}=0.075$, Rayleigh number $R a$ $=10^{4}$, Prandtl number $\operatorname{Pr}=7$ and number of wave $\lambda=3.5$. In addition, the values of the average Nusselt number both for convection and radiation as well as mean bulk temperature and average velocity field are shown graphically.

The effect of emissivity on natural convection inside the solar collector is studied. The influence of $\varepsilon$ on the thermal and flow fields are presented in Fig. 5 (a) - (b) while $\psi=0^{0}$. Surface radiation significantly modifies the temperature distribution inside the collector. As we increase the value of the emissivity, the change in the temperature distribution is less evident. As the emissivity is increased, the temperature distribution at the top cover of the collector becomes more uniform and the isotherms become more parallel to the hot wall increasing the temperature gradient at the wall. This improves the amount of heat transfer by conduction from the hot wall. As the values of emissivity approach almost unity, the temperature gradient near the top cover plate is slightly reduced and natural convection is also weakened with compared to radiation. This behavior is quantified in Fig. 7(i) that shows the average convective and radiative Nusselt numbers calculated at the hot wall. With rising $\varepsilon$ the temperature distributions become distorted resulting in an increase in the overall heat transfer from the transparent cover plate to the wavelike absorber. This result can be attributed to the dominance of the emissivity property.

The effect of surface radiation on the velocity field is shown in Fig. 5 (b). Six primary recirculation cells occupying the whole collector is found at the lowest value of the emissivity $(\varepsilon=0.1)$. As well as two tiny eddies appear near the left and right vertical walls in this case. In each wave, the right and left vortices rotate in counter clockwise and clockwise direction respectively. There are no major qualitative changes in the streamlines as we increase the emissivity but the intensity of the flow is varied. This happens due to greater velocity of heated fluid. If emisivity of the cover plate rises, then more heat is directly transmitted from this surface to the bottom undulating absorber. The working nanofluid then becomes more heated. In addition more perturbation is observed in the streamlines at $\varepsilon=0.98$ because of growing emissivity property of the cover plate.

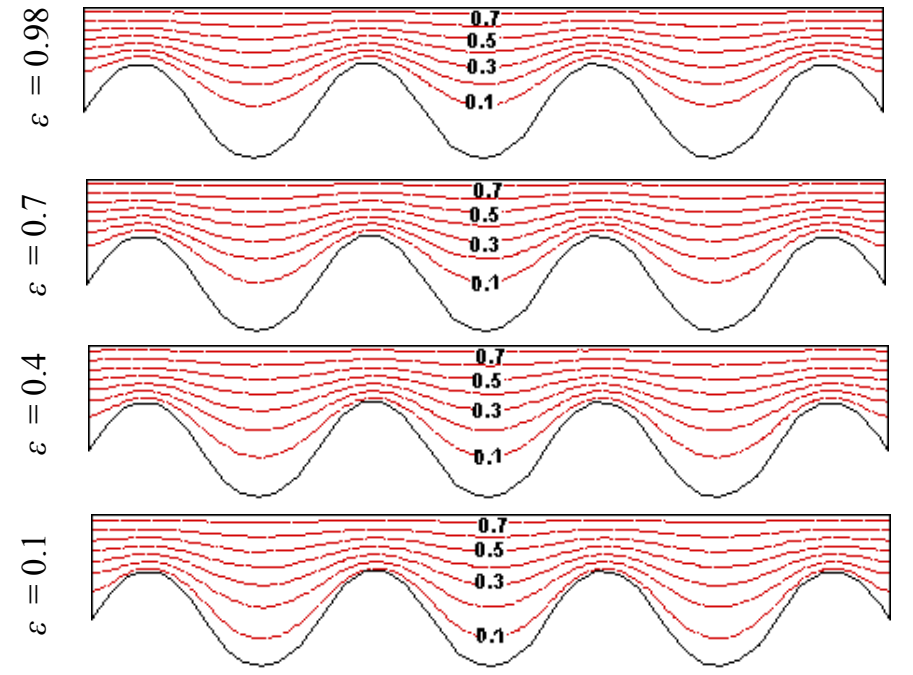

(a)

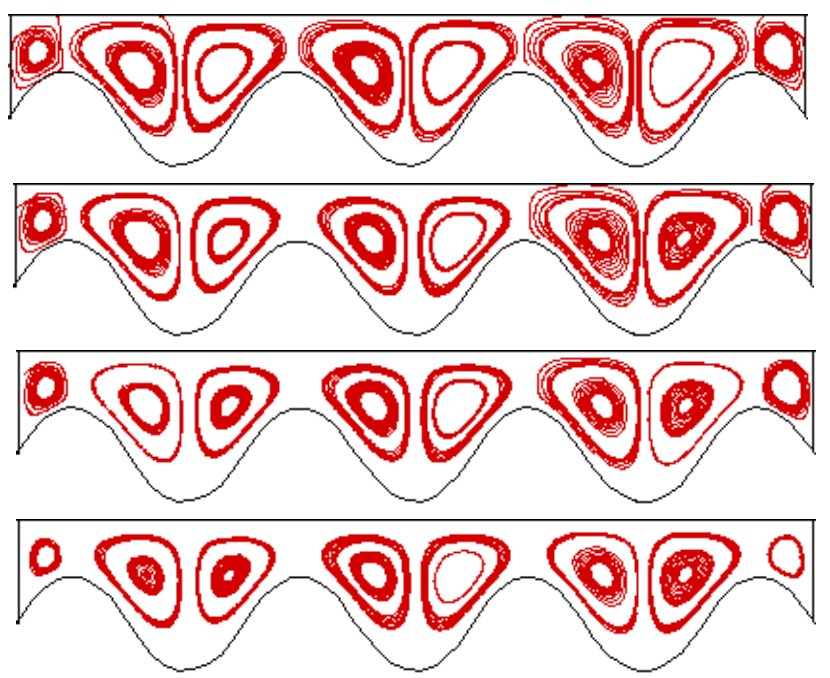

(b)

Fig. 5: Effect of $\varepsilon$ on (a) Isotherms and (b) Streamlines at $\psi=0^{0}$

Fig. 6 (a)-(b) exposes the thermal current activities and fluid flow for various tilted angle $\psi\left(=0^{0}-80^{\circ}\right)$. In this figure we observe that as the tilted angle enhances from $0^{\circ}$ to $80^{\circ}$, the isothermal contours tend to get affected considerably. In addition, these lines corresponding to $\psi=80^{\circ}$ become compressed at right side of each wave whereas initially $\left(\psi=0^{0}\right)$, the thermal lines are symmetric corresponding to vertical midline in each wave. In absence of inclination angle the isotherms cover the whole region of the solar collector due to comparatively higher temperature of the working water- $\mathrm{Al}_{2} \mathrm{O}_{3}$ nanofluid where the contour lines mimic the wall's (absorber) profile. At this stage the cover plate gets full solar energy. Consequently the nanofluid can carry more heat than other cases of tilted angle. This is happened because the top cover plate of the solar collector can't absorb heat properly from the sun with the increasing tilted angle.

The fluid flow covers the entire collector at the absence of $\psi$ forming few (eight) eddies in Fig. $6(\mathrm{~b})$. At $\psi=30^{0}$, the number of vortices devalues from eight to three near the bottom corrugated surface. As well as these vortices are larger than the case of the lowest $\psi$. Due to the gravitational effect i.e. buoyancy effect, the interaction among the nanofluid particles in the solar collector 
increases with the elevation of the tilted angle. The streamlines have no significant change due to rising $\psi$ from $30^{\circ}$ to $80^{\circ}$ except the core of the vortices becomes slightly bigger.

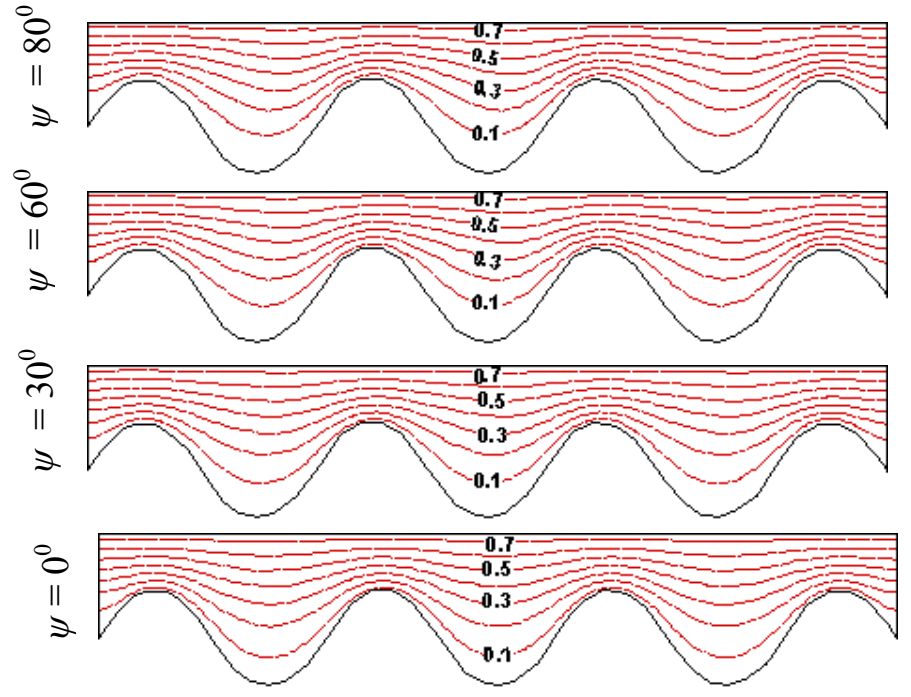

(a)
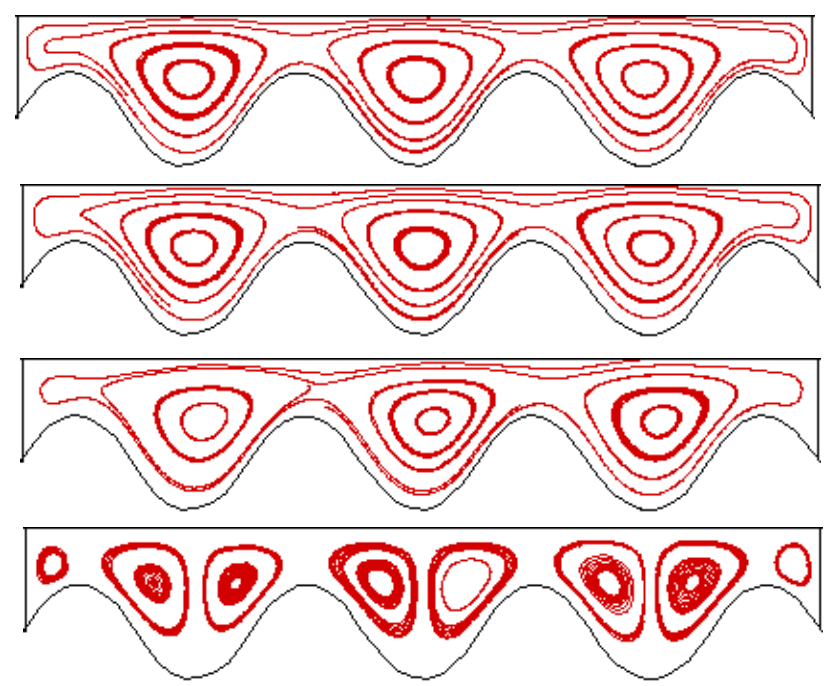

(b)

Fig. 6: Effect of $\psi$ on (a) Isotherms and (b) Streamlines at $\varepsilon=0.1$

The change of the temperature distribution is significant between convection and radiation. The average Nusselt (convective and radiative) numbers, average temperature $\left(\theta_{a v}\right)$ and mean velocity field $\left(\omega_{a v}\right)$ along with the emissivity $(\varepsilon)$ are depicted in Fig. 7(i)(iii). It is seen from Fig. 7(i) that $N u_{c}$ enhances slowly due to growing radiation parameter. The radiative average Nusselt number $\left(N u_{r}\right)$ rises strongly with increased emissivity. It increases much more than the reduction of the convective Nusselt number so the overall Nusselt number at the top of the cavity is highly significant. The rate of heat transfer for water-alumina nanofluid is found to be effective for higher thermal conductivity of solid nanoparticles. Rate of convective heat transfer enhances by $6 \%$ for nanofluid whereas this rate for radiation is $9 \%$ with the variation of $\varepsilon$ from 0.1 to 0.98 . In addition, Fig. 7(ii) shows that $\left(\theta_{a v}\right)$ grows sequentially for all $\varepsilon$. Fig. 7(iii) describes the enhancing phenomena in the $\omega_{a v}-\varepsilon$ profile.

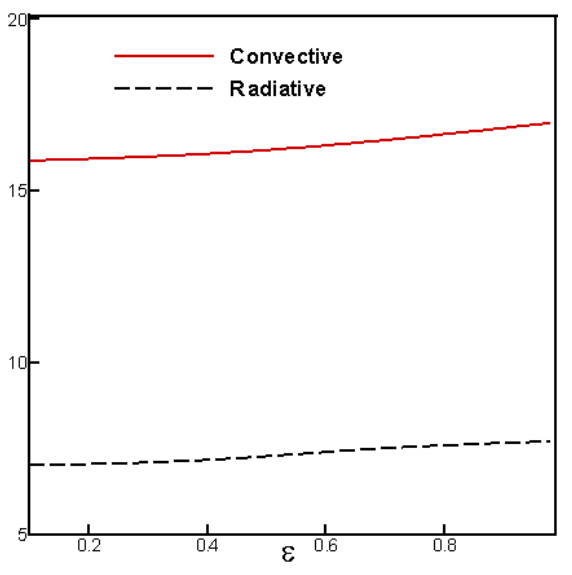

(i)

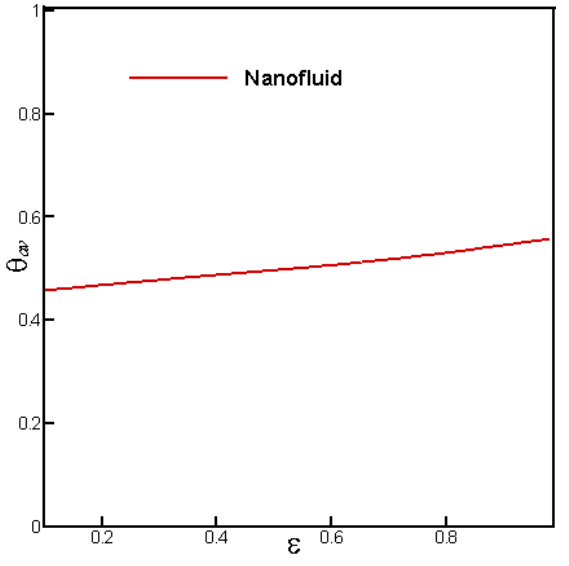

(ii)

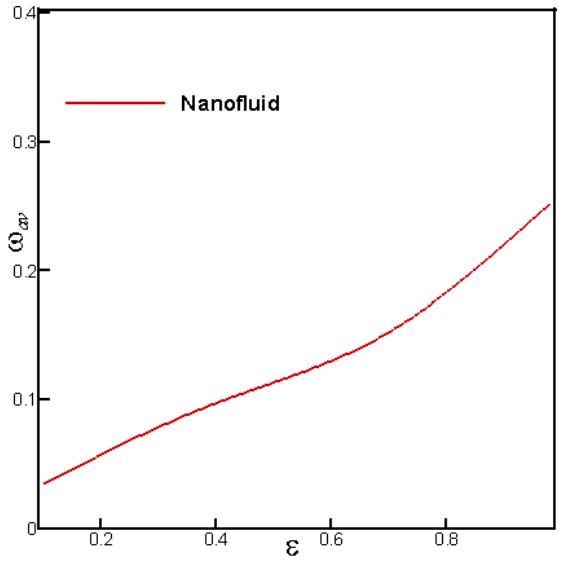

(iii)

Fig. 7: Effect of $\varepsilon$ on (i) heat transfer, (ii) $\theta_{a v}$ and (ii) $\omega_{a v}$ at $\psi=0^{0}$ 


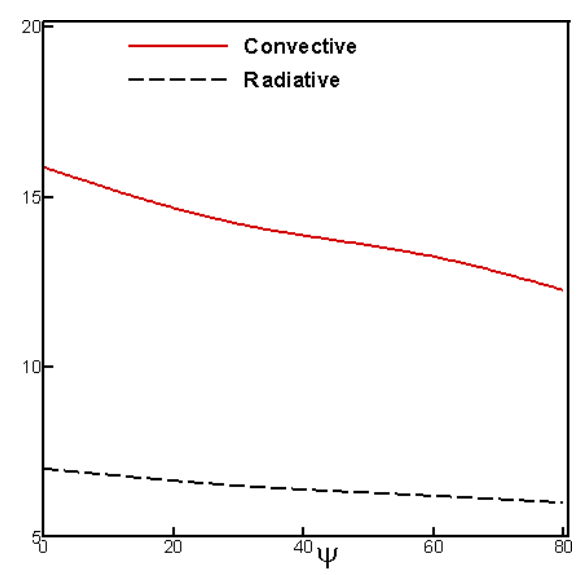

(i)

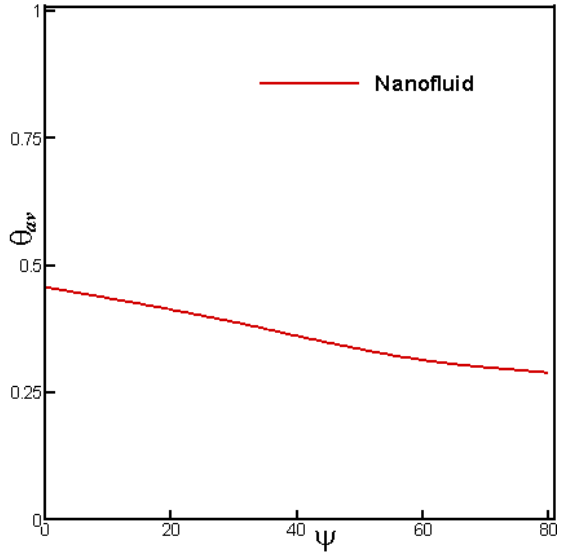

(ii)

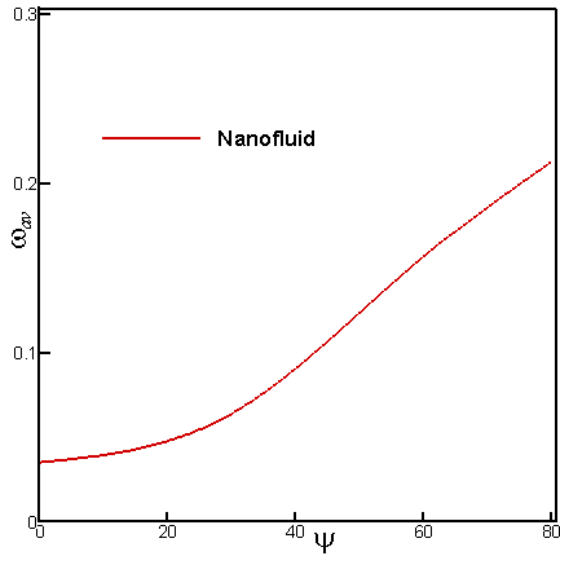

(iii)

Fig. 8: Effect of $\psi$ on (i) heat transfer (ii) $\theta_{a v}$ and (iii) $\omega_{a v}$ at $\varepsilon=0.1$

Fig. 8(i)-(iii) displays the $N u_{c}, N u_{r}, \theta_{a v}$ and $\omega_{a v}$ for the effect of tilted angle $\psi$. Mounting $\psi$ diminishes average Nusselt number for both convection and radiation. From Fig. 8 (i), it is found that, rate of convective and radiative heat transfers decrease by $22 \%$ and $14 \%$ with the increasing values of $\psi$ from $0^{\circ}$ to $80^{\circ}$. On the other hand, $\theta_{a v}$ devalues due to the variation of $\psi$ as temperature of fluid grows down with growing $\psi$. The average sub domain velocity $\left(\omega_{a v}\right)$ profile has notable changes with different values of tilted angle.

\section{Conclusion}

The influences of radiation parameter and tilted angle on natural convection boundary layer flow inside a solar collector with water- $\mathrm{Al}_{2} \mathrm{O}_{3}$ nanofluid are accounted. Various emissivity and tilted angle have been considered for the flow and temperature fields as well as the convective and radiative heat transfer rates, mean bulk temperature of the nanofluid and average velocity field in the collector while $\operatorname{Ra}, \operatorname{Pr}$ and $\phi$ are fixed at $10^{4}, 7$ and $5 \%$ respectively. The results of the numerical analysis lead to the following conclusions:

- The structure of the fluid streamlines and isotherms within the solar collector is found to significantly depend upon the $\varepsilon$ and $\psi$.

- The $\mathrm{Al}_{2} \mathrm{O}_{3}$ nanoparticles with the highest $\varepsilon$ and in absence of $\psi$ are established to be most effective in enhancing performance of heat transfer rate.

- Mean nanofluid temperature diminishes with rising tilted angle $\psi$ and falling emissivity $\varepsilon$.

- Average velocity field increases due to growing both parameters.

A future work is the presentation of the effect of the solid volume fraction. Introducing the values of solid volume fraction $\phi$ from the range $0 \%$ (base fluid) to approximately $6 \%$ in the effective properties of nanofluid such as density, heat capacitance, thermal expansion coefficient, thermal diffusivity, dynamic viscosity and thermal conductivity included in the governing equations ould be a worthwhile investigation in the future.. Overall, the analysis also defines the operating range where water- $\mathrm{Al}_{2} \mathrm{O}_{3}$ nanofluid can be considered effectively in determining the level of heat and mass transfer augmentation.

\section{Nomenclature}

$\begin{array}{ll}A & \text { Area of glass cover plate }\left(\mathrm{m}^{2}\right) \\ A_{m} & \text { Dimensionless amplitude of wave } \\ C_{p} & \text { Specific heat at constant pressure }\left(\mathrm{KJkg}^{-1} \mathrm{~K}^{-1}\right) \\ g & \text { Gravitational acceleration }\left(\mathrm{m} \mathrm{s}^{-2}\right) \\ h & \text { Local heat transfer coefficient }\left(\mathrm{W} \mathrm{m}^{-2} \mathrm{~K}^{-1}\right) \\ k & \text { Thermal conductivity }\left(\mathrm{Wm}^{-1} \mathrm{~K}^{-1}\right) \\ L & \text { Length of the fluid valve }(\mathrm{m}) \\ N u & \text { Nusselt number } \\ p & \text { Dimensional pressure }\left(\mathrm{Nm}^{-2}\right) \\ P & \text { Non-dimensional pressure }\end{array}$




\begin{tabular}{ll}
$P r$ & Prandtl number \\
$R a$ & Rayleigh number \\
$T$ & Dimensional temperature $(\mathrm{K})$ \\
$T_{i}$ & Initial temperature of nanofluid $\left({ }^{\circ} \mathrm{K}\right)$ \\
$u, v$ & Velocity components $\left(\mathrm{ms}^{-1}\right)$ along $x, y$ direction respectively \\
$U, V$ & Dimensionless velocity components along $X, Y$ direction respectively \\
$x, y$ & Cartesian coordinates $(\mathrm{m})$ \\
$X, Y$ & Non-dimensional Cartesian coordinates \\
Greek symbols & \\
$\alpha$ & Thermal diffusivity $\left(\mathrm{m}^{2} \mathrm{~s}^{-1}\right)$ \\
$\beta$ & Thermal expansion coefficient $\left(\mathrm{K}^{-1}\right)$ \\
$\varepsilon$ & Emissivity \\
$\phi$ & Solid volume fraction \\
$\theta$ & Non-dimensional temperature \\
$\mu$ & Dynamic viscosity of the fluid $\left(\mathrm{Kg} \mathrm{m}^{-1} \mathrm{~s}^{-1}\right)$ \\
$v$ & Kinematic viscosity of the fluid $\left(\mathrm{m}^{2} \mathrm{~s}^{-1}\right)$ \\
$\rho$ & Density of the fluid $\left(\mathrm{Kg}^{-3}\right)$ \\
$\lambda$ & Number of wave \\
$\sigma$ & Stefan Boltzmann constant \\
$\Psi$ & Tilted angle $\left({ }^{0}\right)$ \\
$\omega$ & Dimensionless velocity field \\
Subscripts & \\
$a v$ & Average \\
$c$ & Cold \\
$F$ & Base fluid \\
$n f$ & Heated wall \\
$w$ & Nanofluid \\
& Solid particle \\
& \\
\hline &
\end{tabular}

\section{References}

Basak, T., Roy, S., Pop, I., 2009. Heat flow analysis for natural convection within trapezoidal enclosures based on heatline concept, Int. J. Heat Mass Transfer, Vol. 52, pp. 2471-2483.

Brinkman, H.C., 1952. The viscosity of concentrated suspensions and solution, J. Chem. Phys., Vol. 20, pp.571-581.

Dechaumphai, P., 1999. Finite Element Method in Engineering, 2nd ed., Chulalongkorn University Press, Bangkok.

Gao, W., 1996. Analysis and performance of a solar air heater with cross corrugated absorber and back-plate, MS thesis, Yunnan Normal University, Kunming.

Gao, W., Lin, W., Lu, E., 2000. Numerical study on natural convection inside the channel between the flat-plate cover and sinewave absorber of a cross-corrugated solar air heater, Energy Conversion \& Management, Vol. 41, pp.145-151.

Hetsroni, G., Rozenblit, R., 1994. Heat transfer to a liquid-solid mixture in a flume. Int. J. Multiph. Flow, Vol. 20, No. 4, pp. 671689.

Ho, CD, Chen TC, 2006. The recycle effect on the collector efficiency improvement of double-pass sheet-and-tube solar water heaters with external recycle, Renew. Energy, Vol. 31, No. 7, pp.953-97.

Hussain, A., 2006. The performance of a cylindrical solar water heater, Renew. Energy, Vol. 31, No. 11, pp. $1751-1763$.

Hwang, Y., Lee, JK., Lee, CH., Jung, YM., Cheong, SI., Lee, CG., Ku, BC., Jang, SP., 2007. Stability and thermal conductivity characteristics of nanofluids, Thermochimica Acta, Vol. 455, No. 1-2, pp.70-74.

Kolb, A., Winter, ERF., Viskanta, R., 1999. Experimental studies on a solar air collector with metal matrix absorber, Solar Energy, Vol. 65, No. 2, pp. 91-98.

Konttinen, P., Lund, PD., Kilpi, RJ., 2003. Mechanically manufactured selective solar absorber surfaces, Solar Energy Mater Solar Cells, Vol. 79, No. 3, pp. 273-283.

Kreith, F., Kreider, JF.., 1978. Principles of solar engineering, New York, McGraw-Hill.

Lin, KC., Violi, A., 2010. Natural convection heat transfer of nanofluids in a vertical cavity: Effects of non-uniform particle diameter and temperature on thermal conductivity, International Journal of Heat and Fluid Flow, Vol. 31, pp. $236-245$.

Lund, KO., 1986. General thermal analysis of parallel-flow flat-plate solar collector absorbers, Solar Energy, Vol. 5, pp. 443.

Maxwell-Garnett, J.C., 1904. Colours in metal glasses and in metallic films, Philos. Trans. Roy. Soc. A, Vol. 203, pp. 385-420.

Molineaux, B., Lachal, B., Gusian, O., 1994. Thermal analysis of five outdoor swimming pools heated by unglazed solar collectors, Solar Energy, Vol. 53, No. 1, pp. 21-26. 
Nag, A., Misra, D., De, KE., Bhattacharya, A., Saha, SK., 1989. Parametric study of parallel flow flat plate solar collector using finite element method, In: Numerical Methods in Thermal Problems, Proceedings of the $6^{\text {th }}$ International Conference, Swansea, UK.

Natarajan, E. \& Sathish, R., 2009. Role of nanofluids in solar water heater, Int J Adv Manuf Technol, DOI 10.1007/s00170-0081876-8.

Noorshahi, S., Hall, CA., Glakpe, EK., 1996. Natural Convection in a Corrugated Enclosure with Mixed Boundary Conditions, ASME Journal of Solar Energy Engineering, Vol. 118, pp. 50-57.

Orel, ZC., Gunde, MK., Hutchins, MG., 2002. Spectrally selective solar absorbers in different non-black colours, Proceedings of WREC VII, Cologne on CD-ROM.

Piao, Y, Hauptmann, EG, Iqbal, M., 1994. Forced convective heat transfer in cross-corrugated solar air heaters, ASME Journal of Solar Energy Engineering, Vol. 116, pp.212-214.

Piao, Y., 1992. Natural, forced and mixed convection in a vertical cross corrugated channel, MS thesis, The University of British Columbia, Vancouver.

Rao, PP., 1977. Two-dimensional analysis of a flat plate solar collector, J. Energy, Vol.1, pp.324.

Saleh, H., Roslan, R., Hashim, I., 2011. Natural convection heat transfer in a nanofluid-filled trapezoidal enclosure, International Journal of Heat and Mass Transfer, Vol. 54, pp. 194-201.

Soltau, H., 1992. Testing the thermal performance of uncovered solar collectors, Solar Energy, Vol. 49, No. 4, pp. $263-272$.

Stasiek, JA., 1998. Experimental studies of heat transfer and fluid flow across corrugated-undulated heat exchanger surfaces, Int. $J$. Heat Mass Transfer, Vol. 41, pp. 899-914.

Sukhatme, SP., 1991. Solar energy, principles of thermal collection and storage, New Delhi, Tata McGraw-Hill.

Taylor, C., Hood, P., 1973. A numerical solution of the Navier-Stokes equations using finite element technique, Computer and Fluids, Vol. 1, pp. 73-89.

Tripanagnostopoulos, Y, Souliotis, M., Nousia, Th., 2000. Solar collectors with colored absorbers, Solar Energy, Vol. 68, pp. 343356.

Wazwaz, J., Salmi, H., Hallak, R., 2002. Solar thermal performance of a nickel-pigmented aluminium oxide selective absorber, Renewable Energy, Vol. 27, pp. 277-292.

Xiaowu, W., Hua, B., 2005. Energy analysis of domestic-scale solar water heaters, Renewable Sustainable Energy Rev., Vol. 9, No. 6, pp. 638-645.

Xuesheng, W., Ruzhu, W., Jingyi, W., 2005. Experimental investigation of a new-style double-tube heat exchanger for heating crude oil using solar hot water, Appl. Therm. Eng., Vol. 25, No. 11-12, pp. 1753-1763.

\section{Biographical notes}

Rehena Nasrin received M. Sc. and M. Phil. from University of Dhaka and Bangladesh University of Engineering and Technology, Bangladesh in 2002 and 2009 , respectively. Now she is Assistant Professor in the Department of Mathematics, Bangladesh University of Engineering and Technology, Bangladesh. She is a Ph. D. student in Nanofluid with Computational Fluid Dynamics.

M. A. Alim received M. Phil. and Ph. D. from Bangladesh University of Engineering and Technology, Bangladesh and Loughborough University, Loughborough, Leicestershire, UK respectively. Now he is Professor in the Department of Mathematics, Bangladesh University of Engineering and Technology, Bangladesh. He published more than hundred papers in various international journals in the field of Computational Fluid Dynamics. He is reviewer of more than twenty five international journals.

Received June 2012

Accepted July 2012

Final acceptance in revised form July 2012 